\title{
Evolution of the Early Solar System in Terms of Big History and Universal Evolution
}

Leonid Grinin

Eurasian Center for Big History \& System Forecasting, Oriental Institute, Russian Academy of Sciences

\begin{abstract}
The present contribution is devoted to some aspects of history and evolution of the early Solar system. The origin of the Sun, Earth, other planets and its satellites has long been a matter of great concern for people.

Over the past few decades astronomers and cosmologists have considerably advanced in the perception of the structure, history, and evolution of the Solar System. However, one can hardly speak about a proper narrative here; we more often work with hypotheses. The present paper is structured as follows. First, it outlines the history of formation of the Solar system in the first hundred million years of its existence, when the most considerable changes took place. Then while describing certain formative processes we show the opportunities to define them in terms of evolutionary laws and rules. Of course, this paper presents only a few such laws and rules. We suppose that the present study will be of interest to a reader in two ways. First, there are quite a few consistent and brief surveys of the Solar System history accounting for the latest achievements in astrophysics and cosmology. Meanwhile, they are very important and productive for theorizing part of Big History. Second, the discussion employing the general evolutionary laws and rules allows defining some common features in the formation of the Solar system and especially of its planetary system which are characteristic for every level and stage of Big History. This brings us to the idea of the integrity of Big History not only in historical and systemic terms but also with respect to its integrity in detecting general laws, patterns and mechanisms.
\end{abstract}

Keywords: Solar system, exoplanets, protonebula, dust subdisk, planetesimals, planet embryos, protoplanets, catastrophes, planetary migration, rules and laws of evolution, trigger, struggle for resources, primary systems.

\section{Introduction}

The present contribution is devoted to some aspects of history and evolution of the early Solar system, that is to the first billion years of its existence. This period is crucial for understanding how and why the Solar system has become what we know it. One should point that there are many hypotheses and theories about the formation of planets of the Solar system. Still none of them can explain the whole range of related issues.

This paper is a continuation of my previous work (Grinin 2014) both in the sense of the period and in methodological terms. In my former paper (Ibid.) I considered the key events of the cosmic phase of Big History starting from its Star-Galaxy Era, which I described in terms of universal evolutionary principles. In the present paper I will investigate the evolution and history of the early Solar system and against this background I am going to show the possibility to define a number of events of this history in terms of evolutionary laws and rules.

This approach has been deliberately chosen since it allows amplifying the Big History methodology with the achievements and principles from Evolutionistics. As I wrote elsewhere, although Big History provides unique opportunities to consider the development of the Universe as a single process, one should point that Big History studies tend to pay little attention to such an important aspect as the unity of principles, laws, and mechanisms of evolution at all its levels. I believe that combining the Big History's potential with evolutionary approaches can open wider horizons in this respect. Indeed, the common traits in development, functioning, and interaction can be found in different processes and phenomena within Big History. In this respect the universal character of evolution is expressed in the objective similarities that are detected in many manifestations at all its 
levels. Such an approach opens new perspectives for our understanding of evolution and Big History with their driving forces, vectors, and trends, and for creating a consolidated field for a multidisciplinary research (Grinin 2014, 163-164). This approach also produces a synergistic effect revealing new aspects of our Universe and of the world's integrity.

From the evolutionary point of view I divide the early history of the Solar system into four great epochs.

The first epoch was the formation of protosun and protoplanetary disk from the solar nebula. This was the epoch of formation of 'order out of chaos' in Prigogine and Stengers's terms (1989) lasting for about a million years after the collapse of the protosun cloud.

The second epoch was the formation of solid matter, planet embryos and primary planets. It can be denoted as the epoch of struggle for resources - lasting for about 10-50 million years after the collapse.

The third epoch can be called the epoch of planet migrations and catastrophes - lasting about 600-700 million years about 3.9-3.8 billion years ago.

Finally, the Solar System's current architecture has been established.

The fourth epoch is the so-called Late Heavy Bombardment of the planets and their satellites by planetesimals and meteorites which lasted from 900 million to 3.2 billion years.

As has been mentioned above, the research into the Solar system evolution allowed revealing a significant number of processes and events that can be described in terms of general evolutionary laws and rules. In the present contribution I try to show that there are many similarities and common features manifested in the most different processes and phenomena at various stages and levels of Big History.

I suppose that this contribution will be of interest to the readers in two ways. First, there are quite a few consistent and yet brief surveys of the history of the
Solar system accounting for the latest achievements in astrophysics and cosmology. Meanwhile, they are very important and productive for theorizing part of Big History. Second, the accompanying discussion employing the general evolutionary laws and rules allows us to reveal some patterns in the formation of the Solar system and especially of the planetary system which are common for different levels and stages of Big History. This brings us to the idea of the integrity of Big History not only in historical and systemic terms but also with respect to its integrity in detecting the general laws, patterns and mechanisms.

Due to the scope of the paper I have chosen the related evolutionary rules, laws and patterns only to some (and far not all) events of the early history of Solar system (for details see Grinin 2017a).

\section{The formation of the protosolar system from a gas-dust cloud}

With respect to the Solar system history there are still more hypotheses than proven facts. Yet, year by year the hypotheses concerning certain phenomena are supported by direct observations, for example, as a result of discovery of numerous exoplanets.

The age of the Solar system, determined with the radioactive dating technique from the study of the oldest meteorites is about 4.57 billion years (Shukolyukov and Lugmair 2003; Vityazev and Pecgernikova 2010, 168; Pfalzner et al. 2015). The major features of the system were formed during the first few hundred million years, but the actual narrative of this period is still extremely fragmentary and unreliable.

Over the past two or three decades, there has been elaborated a so-called standard scenario for the formation of a planetary system from a protoplanetary gas-dust disk surrounding a protostar, which allows defining the general outlines of the process.

Supported by numerous direct observations, the model of the birth of stars is generally used to reconstruct the origin of the protosun. The stars are 
usually formed in the densest parts of molecular gasdust clouds, the latter composed mainly of hydrogen and helium and having a temperature approaching to absolute zero. The gas clouds can preserve equilibrium for many millions of years. There is needed a certain impulse (a trigger) to launch the condensation process (and subsequent collapse). Perhaps, for the birth of the Sun such a trigger may have been the shockwave from a nearby supernova about two million years before its collapse started (Adushkin et al. 2008, 276) .

Here we deal with a general evolutionary rule which I have defined as a rule of necessary triggering phenomena or events to launch evolutionary process. On the one hand, this can hardly work without internal readiness of a system; and, on the other hand, even a high-level internal readiness itself can hardly ensure the start of a transformation just as gunpowder cannot be exploded without fire. Without a trigger, a system can for a long time remain potentially ready for transformations and still no changes will occur.

The above-mentioned rule works at all evolutionary levels. For example, there is a wellgrounded hypothesis on the role of the cooling that took place 6-8 million years ago and led to the formation of large open spaces in the East Africa. It promoted the evolution of Hominids named Dryopithecus living in trees into bipedal upright walking Hominids of the Australopithecus or another type (Kessler 2017; Niemitz 2010).

In social evolution the triggering phenomena would be necessary for the formation of an early state. In addition to increasing internal complexity of government and social stratification, a trigger is also needed in the form of an abrupt change in society. The latter may have been a war, an involuntary resettlement or opening of the given society to the outer world (as it happened to the Hawaiians in the end of the late 18th century with James Cook's discovery of the islands, see Grinin 2017b).

Along with condensation of the gas-dust cloud, there starts a contraction, or a free fall controlled by self-gravity, which, according to some assumptions, lasted for ten thousand years (Marove et al. 2008, 225; Motoyama Kazutaka and Tatsuo Yoshida 2003). The ongoing collapse makes the initial fragment of the nebula break into smaller clumps so that it usually can generate many stars. The continuing condensation within the clump makes its matter gradually concentrate thus preparing a transformation into a proto-star. The contraction is accompanied by heating while the structure of the future star is formed, including its core and shells. The center of the protostar gradually heats up.

After the outer and inner cores of the protosun had been formed, the rest of peripheral matter partially flew on the core and added to the mass of the forming star. This process of falling of matter (in the case of a protosun - of gas) onto the surface of a body is called an accretion. After the accretion shell falls essentially onto the protostar, the latter turns into a young star. Meanwhile, its inner temperature reaches several million degrees which launches thermo-nuclear reactions. The formation of the Sun as a star is supposed to take about a million years, but there are estimations prolonging or reducing this time span.

\section{The formation of the protoplanetary bodies, planet embryos and protoplanets}

The protoplanetary disk and its evolution. During the formation of a young star, a circumstellar disk is often formed visible across optical and shorter wavelengths. The leftover matter of the accretion disk is partially scattered into space as well as used in the formation of a pro-toplanetary disk. According to the observations, such disk around the stars exists from 5 to 25 million years.

The difficulty in the reconstruction of planetary formation process for the Solar System is compensated by a vast number of hypotheses and theories which have been developed over two centuries. But none of the hypotheses can explain the whole range of the facts related to the planets so far.

However, the vast majority of cosmologists believe 
that the Sun and planets were formed from a single cloud (protosolar nebula) whose matter differentiated into the Sun and the protoplanetary envelope, the latter evolving into a disk as a result of rotation. The rotation and fragmentation of this proto-planetary disk formed the planets in the course of a new cycle of accumulation of matter in protoplanetary bodies. Most cosmologists proceed from the idea that the planets were formed from cold material, which was later heated by shock wave, radioactivity and other processes. The formation of a protoplanetary disk is supposed to last from one to several million years. The mass of the protoplanetary disk is estimated between 3 and $10 \%$ of the solar mass. Besides, it was spatially distributed and heterogeneous. The dimensions of the accretion disks of the young stars are 100-1000 astronomical units.

The disk was more heated in its inward parts while its external regions remained relatively cool. Some contractions occurred there, which contributed to the emergence of separate gravitational centers of planetary formation. Still the mechanism of this process itself was extremely controversial.

The formation of a dust subdisk. Apparently, the protoplanetary disk was composed of the gas from the protosolar cloud with molecular hydrogen and helium absolutely dominating (all other substances amounting for less than $1 \%$ ). Dust particles though accounting for 0.5 to $1.5 \%$ of mass played a peculiar role. This dust was like microscopic solid particles (water ice, sticky molecules and atoms, in particular iron and other solid matter). As a result of the formation of the protosun which accumulated most part of gas, the dust concentration in the protoplanetary disk increased at the later stage of its evolution. But even more it began to increase as a result of the accretion of dust onto the middle plane of the disk.

Some cosmologists believe that the most probable way of formation of the planet embryos is through the accretion of dust particles onto the equatorial plane of the preplanetary disk (Zasov and Postnov
2011, 199). As a result, a dust-gas subdisk was formed in the center of the disk, but the "dust-gas" ratio in it already varied many times as compared with the surrounding space. The dust grains can also increase in size (due to sticking and pulling). Thus, the potential planetary system passed through a very important transition involving the concentration of solid matter (so far in the form of dust), which played an essential role in the growth of preplanetary bodies, and later planets. According to some models, the near-solar protoplanetary disk would evolve for one to two million years before a dust-enriched subdisk was formed.

Actually, the dust subdisk was comparatively thin and its thickness was by 103-104 times smaller than its radius. It had to be opaque to the sun rays, and therefore, they did not reach the periphery of the disk. Among other things this determined the varying conditions for the formation of planets, depending on the proximity to the protosun.

Here we deal with the general evolutionary rule of importance of heterogeneity and fluctuations. In this context dust can be considered as an element of heterogeneity in the clouds of molecular hydrogen. And the concentration of this solid matter launched the emergence of proto-planetary bodies, and later planets.

At all levels of Big History the evolutionary change requires the presence of critical heterogeneity which can trigger the regrouping of matter or elements in the assemblage. And a new structure and order arise on this basis. Meanwhile, an absolute homogeneity makes evolutionary processes impossible.

For example, a mutation can trigger speciation; whereas the groups of foreigners could play an important role in the transformation of many ethnic groups and early states.

The started formation of pre-planetary bodies. As some cosmologists suppose, for some time due to the gravity and turbulence the subdisk may have contracted while the dust and gas condensations and 
further clusters may have been formed within it. But the debating point is whether the planets have been formed from these dust and gas clumps (as the condensation theory maintains) or already from solid matter. The theory of formation of planets from solid matter is called the theory of successive accretion. Many, if not most cosmologists, consider it the most probable scenario. According to it, the tiny dust particles stick together, first forming small particles of solid matter, and then larger objects that gradually grew into planetary embryos. The particles of solid matter (from small to large kilometer or even thousand kilometer size) are called planetesimals.

The most important stage in the process of planetary embryos formation is the formation of large (entire) solid bodies-planetesimals. All theories and hypotheses agree on this point. However, with respect to the number, size and other dimensions of these large objects, there are considerable discrepancies. There are different estimations of the boundary size (critical for the process) planetesimals. The proponents of the theory of successive accretion of matter by planetesimals hypothetically consider the formation of millions and billions of kilometersized bodies, which gradually increase in the process of swarming. According to the condensation theory the largest objects could reach a thousand-kilometer size.

Among many forces that influenced the concentration and accumulation of matter, transformation of the proto-cloud matter into solid objects, determination of orbits and, in general, the protoplanetary formation, two forces are recognized to play a fundamental role in planet formation: gravity and solar radiation. And both of them directly depend on the distance of the object from the Sun. At the distance between 2 and 4 AU from the Sun, between the orbits of Mars and Jupiter, there is a theoretical boundary called an ice line, or a snow line. The ice line is the location where water has a transition from vapor to solid state since the intensity of solar radiation decreases with distance from stars.
"At the location where the temperature is $160-170 \mathrm{~K}$ so that water has a transition from vapor to solid state line itself, water molecules tend to accumulate as they boil off grains" (Lin 2008, 53). The ice line turns into an ice cluster which promotes creation of planetesimals.

Formation of large planetesimals. When the masses of planetesimals increase, their gravity allows them to attract closely-located particles. Thus, numerous kilometer-size planetesimals actively pick up primary dust. Their growth brought the emergence of the so-called protoplanetary planetesimal swarms. Gradually, there emerged a small-numbered 'elite' consisting of bodies of the size of the Moon or even Mercury. There are many hypotheses concerning the mechanisms of their generation as well as the number (from several to hundred ones). Over time, the orbits of the largest bodies became circular which made them the centers of attraction for surrounding matter thus becoming the planetary embryos. According to calculations, the formation of planetesimals lasted for tens and hundreds thousand years, while the formation of protoplanetary bodies from planetesimals took several million years.

Hypotheses about the growing planetesimals and the struggle for resources. The planetesimals would grow due to the accretion of matter, including gas, as well as to mutual attraction and accidental collisions. But the larger a planetesimal, the stronger is its gravity, and the more intensively it sweeps up its low-mass neighbors. When individual planetesimals' masses become comparable to the mass of the Moon, the gravity significantly increases so they can bounce off the surrounding bodies thus escaping collisions. As a result of struggle, clashes and merges, a small number of large cosmic bodies are formed, called the planetary embryos that dominate in their orbital zones and fight for the leftover matter.

At the same time, the growing planetesimals constantly collide and, sometimes merge or on the contrary, split after blows. The numerous splits allowed the larger bodies to capture more and 
more resources. The already large enough objects continued to grow. Gradually, the processes of selforganization began to prevail in this chaos.

Here we deal with the general evolutionary law of the struggle for resources and living space. The struggle for resources is a common mechanism of selection at all levels of evolution. The struggle for resources is an important constituent both of Darwin's struggle for existence in the biological world and of human economic competition. The advantages, including the accidental ones, play an important role at all levels of evolutionary selection . About the law of struggle for resources, see also below.

\section{Formation of the protoplanetary system}

Problems and hypotheses of the formation of planetary groups. Most researchers believe that the period prior to the formation of the first planets lasted for at least several million years. But the discrepancies in determining its duration are rather considerable depending on whether the researchers consider the formation of the Solar system planets as a simultaneous process or happening at different times. Yet, until quite recently the common idea has been that all planets were formed more or less at the same time. Today more scientists tend to believe that the planets emerged at different times, and the intervals between their formation could be up to millions and tens million years.

Thus, some scholars think that it was Jupiter that came first, then Saturn, and much later the terrestrial planets were formed (see, e.g., Lin 2008; Savchenko and Smaghin 2013; Christian 2004, 60 with reference to Taylor 2002, 59-60); still others believe that the Earth group planets emerged first (see, e.g., Marakushev et al. 2013; Vityazev et al. 1990). Some scholars think that at first the terrestrial planets were similar to the giant planets, but then they would lose their fluid envelopes (see, e.g., Marakushev and Zinovieva 2013; Yazev 2011, 357).

There is also an interesting idea that there has existed not one but two or even more generations of primary planets. There is an opinion that being not properly formed those primary planets would explode and become the asteroid belt. Still others think that Jupiter and Saturn may have pushed the primary planets into the Sun or "ejected" them from the Solar system. Thus, it took more than one attempt to form the current order of the planets in the Solar system.

Here we deal with the rule of the archaic character of primary systems. This refers to primary planets or stars as well as to primary biological species or say, to pristine states (about the latter see Grinin 2008). Systems are not formed mature and stable. They usually undergo several reconfigurations including the cycles of destruction and recreation. That is why the primary systems usually appear archaic while the superior systems would emerge as the secondary or tertiary and have more opportunities for selfregulation. Let us consider the first stars which emerged not later than 200-400 million years after the Big Bang (e.g., see European Commission 2011). It is accepted that the first stars were giant ones, much more massive than most of the later-formed stars (May et al. 2008). Due to the absence of carbon, oxygen and other elements that absorb energy from condensing clouds, the process proceeded more slowly in that epoch; thus, only giant clouds could condense to produce massive stars hundreds times larger than the Sun (Ibid.). Those giant stars lived only for a few million years (the larger is a star, the shorter is its life). Moreover, the first stars contained a small amount of heavy elements. Thus, more than one generation of stars could have changed until the amount of heavy elements gradually increased. The emergence of heavy elements from the 'deadstar stellar leftovers' resembles the formation of fertile soil from the remnants of dead plants. The circulation of matter in the Universe is always observed everywhere and at all levels (this is another evolutionary law, about which see Grinin 2013, 2014). 
The causes of differences in formation models of terrestrial and giant planets. Since the planets of the Solar System are divided into two categories (terrestrial and gas giants), the problem of the difference of their formation patterns becomes essential. Was this formation fundamentally the same in both groups, while the differences were determined by the distance from the Sun, or was the process of formation of different groups of planets essentially different, or were there other combinations?

No doubts that the distance from the Sun defined the peculiarities of the planet formation models. Different orbital periods of planetary embryos (the farther the planet from the Sun, the longer the orbit) effected the opportunities to capture surrounding planetesimals and, respectively, the radius and mass of a protoplanet. The snow line effected a higher concentration of planetesimals and matter in certain regions of the Solar System which could also define the size of planets in different regions.

There are numerous hypotheses explaining the origin of the observed categories of planets. For example, there are arguments that gas giants were probably the first planets to form and take almost all gas, while the Earth-type planets got quite a few resources.

Here we again deal with the law of struggle for resources and note that the distribution of resources in the cosmic world is to the same extent unfair as in biological and social realms. For example, the struggle for resources that among stars and galaxies may proceed in the form of weakening of another object or its destruction (e.g., through a direct transfer of energy and matter from one body to another), in the form of 'incorporation', 'capturing', that is 'annexation' of stars and star clusters by larger groups. There are many cases of galactic coalescences. Thus, some astronomers maintain that throughout a few billions of years our galaxy has 'conquered, robbed, and submitted' hundreds of small galaxies, as there are some evident 'immigrants' within our galaxy, including the second brightest star in the northern sky, Arcturus (Gibson and Ibata 2007, 30). It is widely accepted that the emergence and expansion of a black hole may lead to the 'eating' of the matter of the nearby stars and galaxies. However, the 'eating capacity' of the black holes is greatly exaggerated in popular literature. In systems of double stars or in star-planet systems one may also observe such a form of interaction as the exchange of energy and resources (about cosmic struggle for resources see also Grinin 2013, Ch. 5).

Hypotheses and theories concerning the inner planets. There are three main approaches to the formation of terrestrial planets.

1) A planet's mass increases up to present size via accumulation of planetesimals (and meteorites) which results in a gradual separation of the planet's interior into core, mantle and crust (not in all the planets).

2) The formation of the terrestrial planets following the giant-planet pattern. However, later the terrestrial planets lost gases to space. Respectively, only their internal iron-nickel and silicate cores remained. Thus, the iron silicate nuclei of these protoplanet giants have turned into small independent planets. The stratification on iron nuclei and strong silicate shells prevented their explosive disintegration (Marakushev et al. 2013, 135-37).

3) The impact of Jupiter and Saturn on the formation of the terrestrial planets (see below). Hypotheses and theories about the outer planets. The theory of planetary formation pays special attention to two giant gas planets which account for $92 \%$ of the mass of the whole planetary system (that is, Jupiter and Saturn, but especially Jupiter).

There are two major hypotheses describing the possible patterns of formation of Jupiter and Saturn composed mainly of hydrogen and helium. The first - contraction - hypothesis, explains the gaseous composition of the giant planets by the fact that massive gas-dust condensations - protoplanets - were formed within a massive protoplanetary 
disk, which later in the process of gravitational compression would transform into giant planets. However, this hypothesis does not explain why the composition of Jupiter and Saturn differs from that of the Sun as well as some other problems.

According to the second hypothesis of accretion, the formation of Jupiter and Saturn proceeded through two stages. At the first stage, solid bodies were accumulated similar to the processes with terrestrial planets, and after the mass of the largest bodies reached a critical value (of two to ten and more earth masses), the second stage would imply the accretion of gas onto these already quite massive bodies which took place on a time scale of 105-106 years. At the first stage, some gas from the Jupiter region dissipated so its composition would differ from the solar one, and this was even more evident in the formation of Saturn.

According to the competing contraction hypothesis, the temperature of the giant planets was also high at the early stage, but the dynamics of processes proved to be more reasonable within the accretion hypothesis. The formation of Uranus and Neptune, which contain less hydrogen and helium, is also better explained by the hypothesis of accretion, since most of the gas has already left the Solar System after reaching critical mass.

Still the process of the planet formation is rather slow due to accretion into nucleus. It may take several million years. Some researchers, in addition to the scenario of accretion into the nucleus, also consider that gravitational instability in dense and cool regions of the disk can lead to the formation of planets. The formation of planets due to gravitational instability may take much less time than it may require when they are formed via accretion on the core. There is also a hypothesis suggesting that gas giants are formed by a sudden collapse, leading to the destruction of the primary gas-dust cloud. But most cosmologists deny the possibility of gravitational collapse for planets because of their relatively small masses (recognizing it only for stars).

\section{The planetary migration}

As was previously thought, planets remain in the original orbits since their formation. But recently there has become popular the opinion that it took the planets about a billion years to occupy the current orbits. In its early history the Solar system was different, and it is quite probable that the outer Solar system was much more compact in size while the Kuiper belt was located closer to the Sun. There are many suggestions concerning the migrations of planets; yet, these are just hypotheses.

The change of the orbit of Jupiter and other planets. There are especially many suggestions concerning the migrations of Jupiter and Saturn. According to one of them, this gas giant must have formed within the inner part of the planetary system, near the snow line, when there was still a considerable amount of gas in the disk. So it had to move to its present orbit (Lin 2008). When Jupiter drifted to the Sun dragging Saturn, it functioned as a gravitational bulldozer, "pulling" several earth masses of ice matter into the system (Batygin et al. 2016). There is a hypothesis that about $600-700$ million years after the formation of the Solar system Jupiter began drifting and came into orbital resonance with Saturn. The resonance changed the orbits of these planets since it slowed down their migration inside and sent them back to the outer part of the Solar System. The resonance greatly affected the whole Solar System. In particular, Neptune and Uranus exchanged the orbits since Uranus used to occupy a farther position from the Sun than Neptune (Ibid.; see also Batygin and Brown 2016).

It took some time for the planets to come out of resonance. Over a few million years the chaotic interaction between unstable giants "pushed" Jupiter inward to its present place, and other planets "moved away". Moreover, according to one of the exotic hypothesis in the course of such reconfiguration one of the giants may have been expelled to the interstellar space. Here we mean the hypothetic ninth 
planet which may have existed in the distant past.

Here we again deal with the rule of archaic character of primary systems according to which there are needed some large changes (maybe, even cycles of changes) before a system finds its balance.

In addition, the so-called late era of heavy bombardment, or, more precisely, a certain part of this epoch is probably associated with this resonance event (see Bottke et al. 2012, Gomes et al. 2005) . An immense amount of meteorite precipitation fell on rocky planets during this late period. Relatively recent studies have shown that this was a long era, which ended 3.2 billion years ago, that is, it lasted for almost a billion years.

Collisions and catastrophes in the early history of the Solar system. The most debated are the two supposed catastrophes that occurred during the first hundred million years. The first one was the collision of Venus with Mercury. Venus has a retrograde rotation (counter the rotation of the Sun around its axis) while most other large bodies in the Solar system rotate in the same direction with the Sun. Mercury has a non-proportional nickel-iron core, since its metallic core amounts to 60 or more percent of its total mass (Solomon 2003). There are several possible explanations here. One states this may be the result of a collision of Mercury with a large asteroid and as a result of this tangent blow Mercury has lost most of its mantle and shell (Yazev 2011, 48). There is also a more exotic alternative that Mercury was initially farther from the Sun and besides, it was not a planet but the satellite of Venus from which it later "escaped". This explains both Mercury's small size, more appropriate for a satellite, and the retrograde rotation of Venus. The mainstream theory here is the tidal effect of a large satellite (i.e. of Mercury) which long ago both retarded the planet's orbital motion and even made it rotate in the retrograde direction (Ibid., 57-58).

Another famous hypothesis concerning catastrophes is the idea that between 30 and 100 million years after the formation of the Sun, a Mars- sized planet embryo collided with the proto-Earth and generated a huge amount of debris that later formed the Moon. This assumption has several alternatives. There exists a fascinating hypothesis that for millions years a protoplanet Theia may have orbited close to the proto-Earth and finally collided with it. The collision is thought to occur almost tangentially and at a relatively slow velocity. That is why some of the Earth's and Theia's mantles were ejected to the low earth orbit and from these debris the Moon was formed which started to rotate along circular orbit.

More hypotheses about collisions. We have mentioned above that about 600-700 million years after the collapse of the protosolar nebula Neptune migrated into a new orbit. Recently, a hypothesis has been put forward that there used to be not four but five giant planets in the Solar System, and that the fifth planet collided with migrating Neptune and pulled it to the current orbit while the fifth giant planet had collapsed into a cluster of debris which Neptune threw out into the Kuiper belt, that is, to the outskirts of the Solar System (Taylor Redd 2015; Nesvorný 2011).

Here we deal with a widely spread evolutionary pattern - the one of catastrophes. One can point that drama is characteristic of Big History in its every stage. In particular, a famous hypothesis states that the Cretaceous-Palaeogene extinction was caused by the asteroid impact at Yucatan about 65 million years ago (Harmon 2010). Moreover, catastrophes have considerably affected the course of social evolution as well. Let us give the example of the Black Death in fourteenth-century Europe. Catastrophes are one of the main mechanisms of selection at every Big History level. They may serve as triggers launching some processes, as well as destruct the flawed systems and expand the evolutionary opportunities for increasing variability.

About 3.8 billion of years the giants settled their current orbits. It is considered that after the establishment of the current order of planets and 
satellites there have been no considerable changes in the Solar system. Huge changes occurred with the planets themselves and in their geological structure, climate, atmosphere composition and other characteristics.

\section{Conclusion}

Now we can summarize the described above rules, laws, and patterns of evolution:

- the rule of necessity of triggering phenomena or events to launch the evolutionary process;

- the rule of important heterogeneity and fluctuations;

- the law of struggle for resources and living space;

- the rule of the archaic character of primary systems;

- catastrophes as an essential mechanism of selection.

But these are just a few evolutionary rules and laws. However, much of what we know about trends, patterns, and mechanisms which influenced the transformations within Big History as well as evolutionary laws, rules can be traced already in its cosmic phase. Sometimes in an inchoate and nonsystemic form, or on the contrary, the most vivid manifestations may be found just in the cosmic phase. So when numerous characteristics and features typical for biological and social evolution (e.g., like the struggle for resources) are unexpectedly observed at earlier phases of Big History, one starts perceiving that the universal character of evolution is a reality with numerous manifestations.

\section{References}

Adushkin, Vitaly V., Andrey V. Vityazev, and Galina Pechernikova, "To the Elaboration of the Theory of the Origin and Early Evolution of the Earth", in Issues of the Origin and Evolution of the Biosphere, ed. Eduard Galimov (Moscow: LIBROKOM, 2008), 275-296. In Russian (Адушкин, В. В., Витязев, А. В., Печерникова, Г. В. В развитие теории происхождения и ранней эволюции Земли. Проблемы зарождения и эволюции биосферы: сб. науч. работ / под ред. Э. М. Галимова, с. 275-96. М.: ЛИБРОКОМ).

Batygin, Konstantin and Michael E. Brown, "Evidence for a Distant Giant Planet in the Solar System," The Astronomical Journal 151(2) (2016): 22. URL: http://stacks.iop. org/1538-3881/151/i=2/ $\mathrm{a}=22$.

Batygin, Konstantin, Gregory Laughlin, and Alessandro Morbidelli, "Born of Chaos," Scientific American 5 (314) (2016): 28-37. doi:10.1038/ scientificamerican0516-28.

Bizzarro, Martin et al. "Evidence for a Late Supernova Injection of $60 \mathrm{Fe}$ into the Protoplanetary Disk," Science 316(5828) (2007): 1178-1181. doi:10.1126/science. 1141040.

Bottke, William F et al. "An Archaean Heavy Bombardment from a Destabilized Extension of the Asteroid Belt," Nature 485 (7396) (2012): 7881. doi:10.1038/nature10967.

Christian, David. Maps of Time: An Introduction to Big History (Berkeley: University of California Press, 2004).

Christian, David. "Swimming Upstream: Universal Darwinism and Human History" in Teaching and Researching Big History: Exploring a New Scholarly Field, ed. Leonid Grinin et al. (Volgograd, Russia: Uchitel Publishing House, 2014), 19-40.

European Commission, "EU Marie Curie researcher discovers galaxy 13 billion light years away," MEMO 237 (2011). URL: http://europa.eu/rapid/ 
press-release_MEMO-11-237_en.htm.

Gibson, Brad, and Rodrigo Ibata, "The Phantom of

Dead Galaxies," V mire nauki, June (2007): 29-

35. In Russian (Гибсон Б., Ибата Р. Призраки

погибших галактик. В мире науки, июнь:

29-35).

Gomes, Rodney, and others, "Origin of the

Cataclysmic Late Heavy Bombardment Period of

the Terrestrial Planets," Nature 435 (7041) (2005):

466-69. doi:10.1038/nature03676.

Grinin, Leonid "Early State, Developed State, Mature State: Statehood Evolutionary Sequence," Social Evolution \& History 7 (1) (2008): 67-81.

Grinin, Leonid. The Development of the World in terms of Big History: the Cosmic Evolution (Volgograd: Uchitel, 2013). In Russian (Гринин, Л. Е. Больш.ая история развития мира: космическая эволюция. Волгоград: Учитель).

Grinin, Leonid. "The Star-Galaxy Era of Big History in the Light of Universal Evolutionary Principles," in Teaching \& Researching Big History: Exploring a New Scholarly Field, ed. Leonid Grinin, Leonid et al. (Volgograd: 'Uchitel' Publishing House, 2014), 163-187.

Grinin, Leonid. The Development of the World in terms of Big History: the History and Evolution of the Solar System (Volgograd: Uchitel, 2017a). In Russian (Гринин, Л. Е. Большая история развития мира: история и эволюция Солнечной системы. Волгоград: Учитель).

Grinin, Leonid. "Complex Chiefdoms: Precursor of the State or Its Analogue?" in Chiefdoms: Yesterday and Today, ed. Robert L. Carneiro, Leonid Grinin, and Andrey Korotayev (Clinton Corners - New York: Eliot Werner Publications, Inc., 2017b), 195-232.

Grinin, Leonid, and Andrey Korotayev, "Introduction. At the Junction of Theories and Paradigms," in Evolution: Development within Big History, Evolutionary and World-System Paradigms, ed. Leonid Grinin and Andrey Korotayev (Volgograd: 'Uchitel' Publishing
House, 2013), 5-17.

Gromov, Alexander. The Amazing Solar System (Moscow: EKSMO, 2012). In Russian (Громов А. Н. Удивительная Солнечная система. М.: ЭКСМО).

Harmon, Katherine. "A Theory Set in Stone: An Asteroid Killed the Dinosaurs, After All," Scientific American, March 4 (2010). URL: https:// www.scientificamerican.com/article/asteroidkilled-dinosaurs/.

Kessler, Peter. "Prehistoric World: Hominid Chronology," History Files, 26 (2017). URL: http://www.historyfiles.co.uk/FeaturesAfrica/ HominidChronology 1.htm.

Lin, Douglas N. C.. "The Genesis of Planets," Scientific American 298(5) (2008): 50-59. doi:10.1038/scientificamerican0508-50.

Marakushev, Alexey A. and Nina G. Zinovyeva, "Meteorites and Planets of the Solar System," Prostranstvo i vremya 4(1) (2013). URL: http://jspacetime.com/actual\%20content/t4v1/22279490e-aprovr_e-ast4-1.2013.11.php. In Russian (Маракушев, А. А., Зиновьева, Н. Г. Метеориты и планеты Солнечной системы. Пространство и Время. Т. 4. Вып. 1).

Marakushev, Alexey A. et al."Origin and Evolution of the Solar System," Prostranstvo i vremya 2 (12) (2013): 132-141. In Russian (Маракушев, А. А., Зиновьева, Н. Г., Панеях, Маракушев, Н. А., С. А. Зарождение и эволюция Солнечной системы. Пространство и Время. Вып. 2 (12), с. 132-41).

Marov, Mikhail et al. "From a Proto-Solar Nebula toa Planatary Systam: The Model of the Emergence of the Gas-Dust Disk," in Issues of the Origin and Evolution of the Biosphere, ed. E. Galimov, M. (ed.), (Moscow: Librokom, 2008), 223-274. In Russian (Маров, М. Я., Колесниченко, А. В., Макалкин, А. Б., Дорофеева, В. А., Зиглина, И. Н., Чернов, А. В. От протосолнечного облака к планетной системе: Модель эволюции газопылевого диска. Проблемы зарождения и 
эволюции биосферы: сб. науч. работ / под ред. Э. М. Галимова, с. 223-74. М.: ЛИБРОКОМ).

May,'Brian, Patrick Moore, ‘and Chris Lintott, Bang: The Complete History of the Universe (Baltimore, MD: Johns Hopkins University Press, 2008).

Motoyama, Kazutaka and Tatsuo Yoshida, "High Accretion Rate during Class 0 Phase due to External Trigger," Monthly Notices of the Royal Astronomical Society 344 (2) (2003): 461-67. doi:10.1046/j.1365-8711.2003.06833.x.

Nesvorný, David. Young Solar System's Filth Giant Planet? The Astrophysical Journal 742(2) (2011): L22. doi:10.1088/2041-8205/742/2/L22.

Niemitz, Carsten. "The Evolution of the Upright Posture and Gait - a Review and a New Synthesis," Naturwissenschaften. 97 (2010): 241-263. doi:10.1007/s00114-009-0637-3. PMC 2819487 Freely accessible. PMID 20127307 www. ncbi.nlm.nih.gov/pmc/articles/PMC2819487/

Prigogine, Ilya and Isabelle Stengers, Order Out of Chaos. Man's New Dialogue with Nature (Bantam Books, 1989).

Savchenko, Valery N. and Vladimir P. Smaghin. Conception of Modern Natural Studies. 2 vols. Vol. 2. Planetary, Chemical, Biological, Evolutionary, Philosophy and Methods, and Mega History of the Universe (Vladivostok: VGUES, 2013). In Russian (Савченко, В. Н., Смагин, В. П. Концепции современного естествознания: в 2 т. Т. 2. Планетное, химическое, биологическое, эволюционное, философия и инструменты, мегаистория Вселенной. Владивосток: Изд-во ВГУЭС).

Shklovsky, Igor S. Universe, Life, Mind (Moscow: Nauka, 1987). In Russian (Шкловский И. С. Вселенная, жизнь, разум. М.: Наука).

Solomon, Sean. "Mercury: the Enigmatic Innermost Planet," Earth and Planetary Science Letters 216 (4) (2003): 441-455. doi:10.1016/S0012821X(03)00546-6.

Taylor, Ross. "The Solar System: An Environment for Life?" in To Mars and Beyond: Search for the
Origins of Life, ed. Malcolm Walter (Canberra: National Museum of Australia, 2002), 59-60. Taylor Redd, Nola. Our Early Solar System may have been Home to a Fifth Giant Planet. Science (Aug. 11,2015). doi:10.1126/science.aad1604. http://www.sciencemag.org/news/2015/08/ourearly-solar-system-may-have-been-home-fifthgiant-planet.

Vityazev, Andrey V., Galina V. Pechernikova, and Viktor Safronov, The Terrestrial Planets: Origin and Early Evolution (Moscow: Nauka, 1990). In Russian (Витязев, А. В., Печерникова, Г. B., Сафронов, В. С. Планеты земной группы: Происхождение и ранняя эволюция. М.: Наука).

Yazev, Sergey. Lectures on the Solar System: A Textbook (St. Petersburg: Lan', 2011). In Russian (Язев С. А. Лекции о Солнечной системе: уч. пособ. / Ред. В. Г. Сурдин. СПб.: Лань).

Zasov, Anatoly and Konstantin Postnov, The Course of General Astrophisics (Fryazino: Vek 2, 2011). In Russian (Засов, А. В., Постнов, К. А. Курс общей астрофизики. Фрязино: Век 2). 